\title{
Erratum to: Morpho-Physiological Parameters Associated with Iron Deficiency Chlorosis Resistance and Their Effect on Yield and Its Related Traits in Groundnut
} \author{
Anand Kanatti², Vinod Kumar', Manoj K. Debnath ${ }^{3}$

\section{Erratum to: J. Crop Sci. Biotech. 2016 (JUNE) 19 (2) : 177 187 DOI NO. 10.1007/s12892-016-0005-8}

Ishwar H. Boodi ${ }^{1}$, Santosh K. Pattanashetti ${ }^{1,2^{*}}$, Basavaraj D. Biradar ${ }^{1}$, Gopalakrishna K. Naidu', Virupakshi P. Chimmad

\begin{abstract}
On page 178 , in the $1^{\text {st }}$ line of the third paragraph, the fallowing sentence should be replaced. 'wwIron deficiency in groundnut initially appears as chlorosis on young rapidly expanding leaves which is characterized by interveinal chlorosis.' should now read as: 'Iron deficiency in groundnut initially appears as chlorosis on young rapidly expanding leaves which is characterized by interveinal chlorosis.'
\end{abstract}

On page 180 , in the $7^{\text {th }}$ line of the last paragraph, the fallowing sentence should be replaced. 'Interaction $\left(\mathrm{A}^{\smile} \mathrm{B}\right)$ mean squares showed significant differences for VCR at all five stages, while at specific stages for $\operatorname{SPAD}(60,80$, and $100 \mathrm{~d})$, chlorophyll content ['a' (60 d), 'b' (100 d), and total (100 d)], and peroxidase activity (40 and $100 \mathrm{~d}$ ). should now read as: 'Interaction (A x B) mean squares showed significant differences for VCR at all five stages, while at specific stages for $\operatorname{SPAD}(60,80$, and $100 \mathrm{~d})$, chlorophyll content ['a' (60 d), 'b' (100 d), and total (100 d)], and peroxidase activity (40 and $100 \mathrm{~d}) . '$. And, in the 14th line, the fallowing sentence should be replaced. 'The interaction (A x B) mean squares showed significant difference only for 100-seed weight.' should now read as: 'The interaction $\left(\mathrm{A}^{\smile} \mathrm{B}\right)$ mean squares showed significant difference only for 100 -seed weight.'.
On page 186, in the 10th reference, should be replaced.

Irmak S, C1 1 AN, Yücel H, Kaya Z. 2012. The effects of iron application to soil and foliarly on agronomic properties and yield of peanut (Arachis hypogaea). J. Food Agric. Env. 10(3/4): 417-42

should now read as:

Irmak S, Çıl AN, Yücel H, Kaya Z. 2012. The effects of iron application to soil and foliarly on agronomic properties and yield of peanut (Arachis hypogaea). J. Food Agric. Env. 10(3/4): 417-442

On page 187, in the last reference, should be replaced.

Zuo Y, Ren L, Zhang F, Jiang RF. 2007. Bicarbonate concentration as affected by soil water content controls iron nutrition of peanut plants in a calcareous soil.

In JF Briat, JB Gaymard, Eds, XIII Int. Symp. Iron Nutrition \& Interactions in Plants, Montpellier, France, 3-7 July 2006. Plant Physiol. Bioch. 45(5): 357-364

should now read as:

Zuo Y, Ren L, Zhang F, Jiang RF. 2007. Bicarbonate concentration as affected by soil water content controls iron nutrition of peanut plants in a calcareous soil. In JF Briat, JB Gaymard, Eds, XIII Int. Symp. Iron Nutrition \& Interactions in Plants, Montpellier, France, 3-7 July 2006. Plant Physiol. Bioch. 45(5): 357-364

Also, figure Table 2 and Table 5 should be changed. The updated tables are shown in this erratum.

The online version of the original article can be found under doi: DOI 10.1007/s12892-016-0005-8.

\section{Santosh K. Pattanashetti ${ }^{1}$}

University of Agricultural Sciences, Dharwad - College of Agriculture, Vijayapur 586101, Karnataka, India

E-mail: s.pattanashetti@cgiar.org

Cell: +918978596325 
Table 2. Mean performance of genotypes for morpho-physiological parameters in normal- and deficit- Fe soils across growth stages.

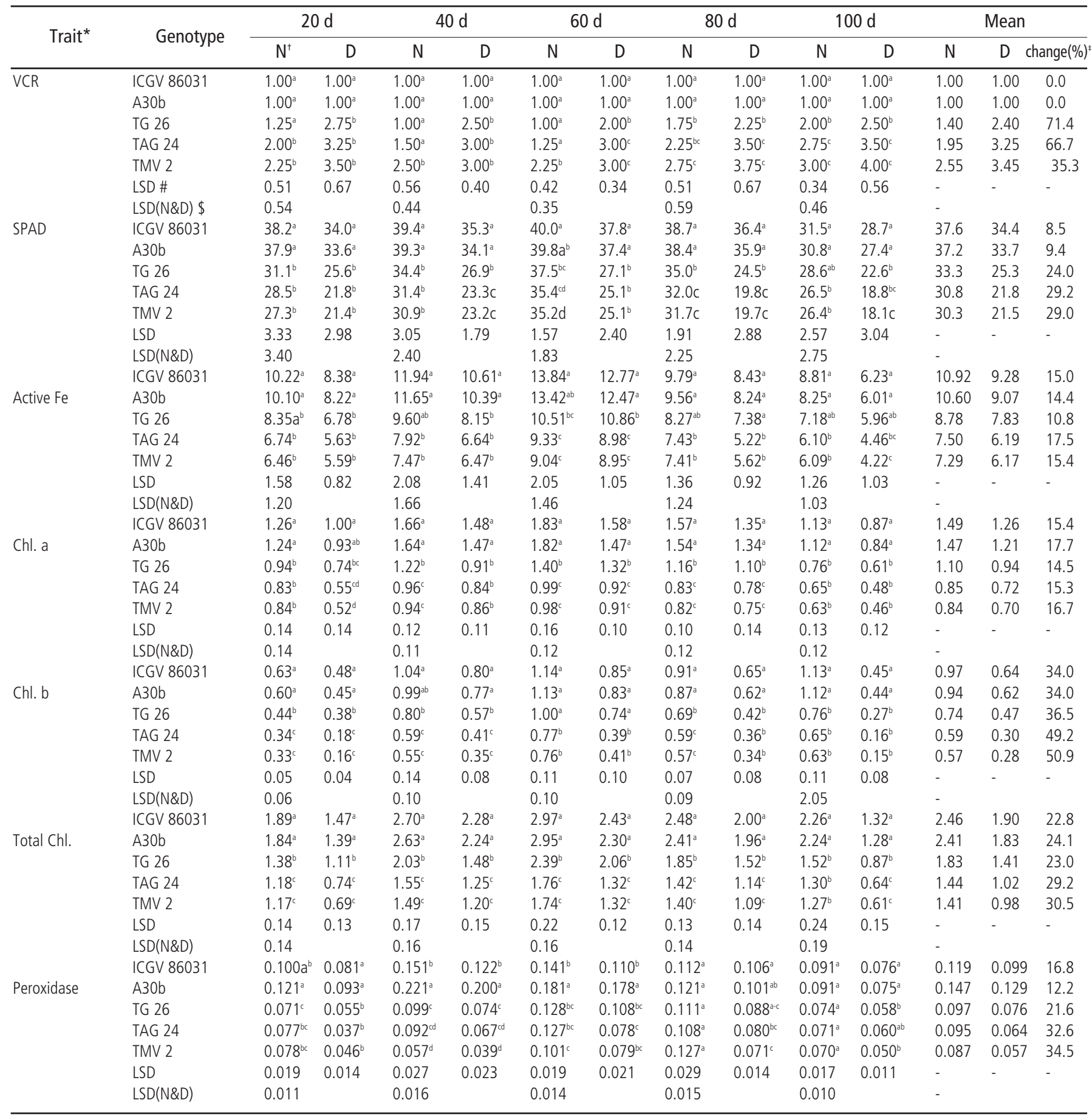

*VCR- Visual chlorosis rating, SPAD- SPAD values, Chl. a- Chlorophyll a, Chl. b- Chlorophyll b, Total Chl.- Total Chlorophyll; $d$ - days after sowing

\# LSD- Least significant difference $(P=0.05)$ for normal- and deficit-Fe soils individually; ${ }^{5}$ LSD(N\&D)- Common LSD $(P=0.05)$ for both normal- and deficit-Fe soils for treatment comparisons; ${ }^{+} \mathrm{N}$ - Normal-Fe soil, D- Deficit-Fe soil; Initials ( $a, b, c$, etc.) given for mean values indicate grouping of genotypes based on Tukey's HSD test within normal-Fe (N) and deficit-Fe (D) conditions; ${ }^{\ddagger}$ Change (\%)- \% Change for mean across five stages between normal- and deficit-Fe i.e. \% increase in $\mathrm{VCR}$, while $\%$ decrease for rest other traits 
Table 5. Associations between mean of morpho-physiological parameters across five stages and yield-related traits

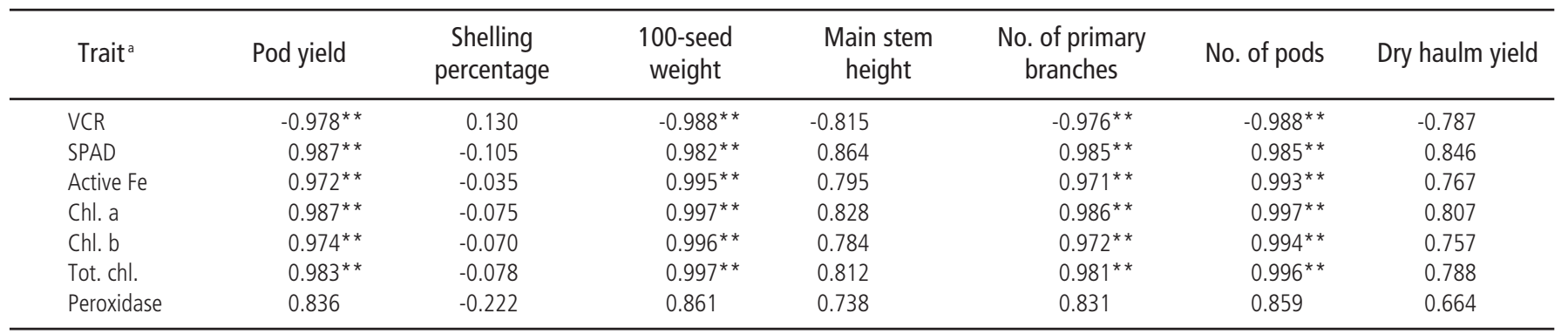

